\title{
Panning for Population Gold: 20 Years of Research at MCHP
}

\section{À la recherche de l'or de la population : 20 ans de recherche au Centre des politiques de santé du Manitoba}

\author{
RANDALL FRANSOO, PHD \\ Research Scientist, Manitoba Centre for Health Policy (MCHP) \\ Assistant Professor, Community Health Sciences, \\ Faculty of Medicine, University of Manitoba \\ Winnipeg, $M B$ \\ GAIL MARCHESSAULT, PHD, PHEC, RD \\ Independent Qualitative Health Researcher \\ Winnipeg, $M B$ \\ CHARLYN BLACK, MD, SCD \\ Associate Director, UBC Centre for Health Services and Policy Research \\ Professor, School of Population and Public Health \\ Vancouver, BC \\ CAROLYN DECOSTER, PHD, RN, MBA \\ Director, Health Services Measurement - Clinical Service Optimization \\ Data Integration, Measurement $\&$ Reporting, Alberta Health Services \\ Calgary, $A B$
}

\begin{abstract}
$\overbrace{\text { his session started with Dr. Marchessault presenting highlights }}$ from her research project, "The Manitoba Centre for Health Policy: A Case Study" (see pages 29-43 of this Special Issue). Semi-structured interviews with 28 par-
\end{abstract} ticipants revealed that a multitude of factors were involved in establishing MCHP. Donald Orchard, then Minister of Health for Manitoba, and Deputy Minister Frank Maynard initiated discussions about creating a research centre. They were motivated by a need for information to guide decisions they faced in an era of financial pressure, by influential presentations from figures including Dr. Fraser Mustard and by the international reputation of 
Drs. Noralou Roos and Leslie Roos. They saw the benefit of having information come from a reliable source outside of government and wanted to "put some science behind some of the decisions we were making." Mr. Orchard was willing to take the political risk in order to advance healthcare in Manitoba. Fortunately, Manitoba had excellent electronic records of the population and their health services use - data that the Rooses had been working with for 15 years, achieving exemplary scholarship. Manitoba was small enough that the entire data system was manageable given the computing power of the day. Small size also facilitated cooperation among managers of different sectors. Leadership from Dr. Brian Postl, head of the University of Manitoba's Department of Community Health Sciences, Dr. John Wade, dean of the Faculty of Medicine, and Dr. Arnold Naimark, president of the University of Manitoba, helped establish an appropriate budget and agenda for research projects, as well as systems to protect academic freedom to publish without government interference. The structure of the MCHP advisory board balances university and government interests, and the process of negotiating research topics ensures that questions of relevance to the government are addressed while taking advantage of the strengths of the data system.

Dr. Black then spoke about the excitement and challenge of assembling a comprehensive data system, building on early research conducted with data from Manitoba Health. This initiative required learning how to transform program-specific data into richer information. These efforts were aimed at informing important and enduring policy and program questions about population health status and its distribution. Based on emerging models of population health (Evans and Stoddart 1990) and an understanding of the strengths and limitations of the data, a conceptual model was developed to guide this work. It quickly became apparent that population-based approaches, together with a broader perspective on health (rather than a focus on specific disease states) would provide remarkably powerful insights and perspectives about health and healthcare. While administrative data often lack depth, the breadth of the Manitoba data, both in terms of population coverage and the range of services included, makes conducting rich analyses possible. The process of creating a health information system required extensive effort to acquire and organize the data and also to develop approaches to conduct both population-based (i.e., based on where people lived, not just where they used services) and more traditional provider- and organization-based (i.e., based on where services are delivered) approaches. It also required the development of measurement tools for a large number of key concepts - for example, to report on "health status" and "need" for healthcare across populations, as well as measures for key concepts such as access to care, effectiveness and cost of services provided, and performance in delivering services. The combination of these measures and approaches has provided a powerful foundation for developing more focused information in response to specific policy questions.

Dr. DeCoster discussed some of MCHP's communications successes, including her role in creating the first short summary of a research report, which became the universally popular "four-pagers." These plain-language summaries remain a central part of MCHP's dissemination strategy, appealing to a broad range of readers. Dr. DeCoster also talked about her research on waiting times, and how that early work at MCHP has grown into a key focus of 
her ongoing research interests and partnerships. Key findings from analyses of wait times for cataract surgery include the revelation that having a parallel private system did not reduce wait times for cataract surgery in the public sector in Manitoba, and that rates of injury increase with duration of wait time. This avenue of research connected Dr. DeCoster to a network of researchers and the Western Canada Wait List Project, which now involves a large group of researchers from across the country who currently investigate issues of appropriateness and outcomes. She concluded by noting that knowledge translation at MCHP historically involved communications, collaboration and documentation, and that these three facets remain centrally important in her work today.

All three speakers noted the importance of teamwork in the MCHP environment, including reaching out to stakeholders in policy and program areas to ensure validity of research techniques and appropriate context for interpreting the results.

\section{REFERENCE}

Evans, R.G. and G.L. Stoddart. 1990. "Producing Health, Consuming Health Care." Social Science and Medicine 31(12): 1347-63. 